\title{
HIV positive status disclosure and highly active antiretroviral therapy adherence among people living with hiv in ambo hospital, west shewa zone, oromia region, Ethiopia
}

\begin{abstract}
Background: HIV sero status disclosure and adherence to Highly Active Antiretroviral Therapy (HAART) medication are important for the prevention and control of HIV/AIDS Little is known about the relationship between HIV positive status disclosure and highly active anti-retroviral therapy (HAART) adherence in developing countries including Ethiopia. The aim of this study was to explore the relationship between HIV status disclosure and HAART adherence.
\end{abstract}

Method: A cross-sectional study using quantitative research approach supplemented by qualitative methods was conducted from January to February 2012 on 420 people living with HIV (PLHIV) attending ART clinic in Ambo Hospital. Simple random sampling method was used to select the study participants. Data were collected through face to face interview and focus group discussion using pre-tested structured questionnaire and semi structured interview guides, respectively. Crude and adjusted odds ratios using logistic regression analysis were used to explore associations between different variables and HIV status disclosure and ART adherence.

Results: The study revealed that the prevalence of HIV status disclosure to at least one person and highly active anti-retroviral therapy adherence were $86.2 \%$ (95\% CI: 82.52 $89.34)$ and $86 \%$ (95\% CI: 82.2-89.13) respectively. Prevalence of HAART adherence among PLHIV who disclosed their sero status was $88.7 \%$ (95\% CI: 84.95-91.75) where as the prevalence of HAART adherence among PLHIV who did not disclose their status was $69 \%(95 \% \mathrm{CI}: 55.46-80.46)$. HIV status disclosure to at least one person $(\mathrm{AOR}=3.42$, 95\%CI: $1.60-7.29)$ and being literate $(\mathrm{AOR}=2.13,95 \% \mathrm{CI}: 1.08-4.22)$ were significantly associated with HAART adherence.

Conclusion: HIV positive status disclosure was a significant predictor of HAART adherence. Hence, intervention programs to improve HAART adherence should consider the potential benefits of HIV status disclosure.

Keywords: Disclosure, HAART adherence, Ambo, Ethiopia
Volume 5 Issue 2 - 2016

\author{
Shewaye Fituma Natae, Digafe Tsegaye \\ Nigatu \\ Department of Public Health, Ambo University, Ethiopia
}

Correspondence: Shewaye Fituma Natae, Lecturer at department of Public Health, College of Medicine \& Health Sciences, Ambo University, Ambo, Ethiopia, Email shewayeftm@gmail.com

Received: August 09, 2016 | Published: September 02, 2016

\section{Background}

In 2012 an estimated 35.3million people were living with Human Immunodeficiency Virus (HIV), 2.3 million new HIV infections and 1.6 million AIDS related death occurred globally in 2012. ${ }^{1}$ According to Ethiopia Demographic and Health Survey (EDHS) report of 2011, adult prevalence of HIV infection in Ethiopia was $1.5 \%$. The prevalence was higher among women (1.9\%) than men $(1.0 \%) .2$

HIV status disclosure is important for HIV prevention and highly active anti- retroviral therapy (HAART) adherence. ${ }^{3}$ Disclosure provides many important benefits to the infected individual and to the public. It motivates sexual partners to seek HIV testing, change behavior and ultimately decrease transmission of HIV. For instance, women who disclose their status to their partners may be more likely to participate in prevention of mother to child transmission (PMTCT) programmes. By adequately addressing the emotional, social, and practical sequel of her positive status, she may be more willing to adopt and maintain health behaviors such as cessation of breastfeeding or adherence to treatment regimens. ${ }^{4}$
However, disclosure of HIV status may have potential risk for the infected individual, such as disruption of family relationship, stigma and rejection/discrimination, and blame..$^{5}$ Disclosure was less likely to have occurred if the woman had experienced two or more of the different types of violence. ${ }^{6}$ The fear of stigmatization may force PLHIV (People living with HIV) to hide their HIV status. For instance, a study done in Botswana on barriers to antiretroviral adherence to patients living with HIV infection and AIDS showed that due to the fear of stigma, 69\% kept their HIV status secret from their families, and a further $94 \%$ kept it secret from their society. ${ }^{7}$

Initiatives to provide antiretroviral therapy sometimes require that patients disclose to a supportive individual in their network, on the basis of a large body of evidence indicating that disclosure facilitates initiation of and adherence to antiretroviral therapy, whereas worries about disclosure contribute to secrecy and missed medications. ${ }^{4,8}$ To encourage beneficial disclosure, countries need to establish safe social and legal environments in which more people are willing and able to get tested for HIV and are empowered and encouraged to change their behavior according to the results. ${ }^{9}$ 
Disclosure can have a significant impact on adherence to medical regimens; reduce HIV transmission, access to support services, reductions in mental health symptoms and effective adaptation to living with HIV. A study conducted in Cameroon among HIV infected women and in Uganda among people living with HIV revealed that disclosure of HIV sero status was critical because of its significant links to safer sex practices. ${ }^{10,11}$ A study done in Botswana and New York showed that nondisclosure of positive HIV status to their partner/ relatives was predictor of poor adherence to ART. ${ }^{12,13}$

Other studies done in rural China and Tanzania showed that HIV status disclosure was a significant predictor for access to care. ${ }^{14,15}$ Despite the importance of VCT, ART and PMTCT services in reducing the burden of HIV/AIDS; HIV positive status disclosure and HAART adherence reduce HIV transmission, prevent morbidity and mortality associated with non-disclosure and non adherence. ${ }^{5,8}$ The study was carried out to assess the relationship between HIV sero positive status disclosure and HAART adherence in addition to the magnitude of HIV positive status disclosure and the level of HAART adherence.

\section{Methods and materials}

\section{Study design and population}

Institutional based cross sectional study was conducted from January to February 2012 using quantitative research approach supplemented by qualitative methods. A total of 420 PLHIV attending ART clinic of Ambo Hospital were participated in the study. The sample size was determined by using single population proportion formula by assuming that the prevalence of HAART adherence among PLHIV who disclose their HIV positive sero status was 50\% and $95 \%$ level of significance and 5\% margin of error (precision) the sample size was 384 , by considering $10 \%$ non response rate the final sample size was 422 PLHIV on HAART. A total of 24 PLHIV of four focus group discussions were conducted among PLHIV who were currently on HAART but not participated in the quantitative study were included in the qualitative study.

\section{Study area}

The study was conducted at Ambo Hospital in West Shewa Zone of Oromia Regional State. Ambo town, which is the capital of West Shewa Zone, is located at $114 \mathrm{~km}$ to the West of Addis Ababa. An estimated 76,774 population were inhabitants in the town. There are different levels of both government and private health facilities offering health services in the town. Ambo Hospital is the only Zonal Hospital in West Shewa Zone; currently it provides comprehensive health services (prevention and curative) including VCT, ART and PMTCT services. The ART clinic was established in October 2005. A total of 4019 patient started ART from which 2224 clients were currently on ART and 3006 clients were on pre-ART.

: Preliminary assessment was conducted to identify PLHIV who were on ART at Ambo Hospital from the registration book of the clients. Four thousand and nineteen (4019) PLHIV start ART at Ambo Hospital; of which 3696 PLHIV were 18 years and above. From 3696 PLHIV who where at least 18 years 792(21\%), 496(13.4\%), $177(4.8 \%)$ and $7(0.2 \%)$ clients were transferred out, default, died and lost to follow up respectively and only 2224(60.2\%) PLHIV were on ART at Ambo Hospital during the study period. One thousand PLHIV who fulfilled the inclusion criteria were identified during the study period (Jan 1- Feb 30, 2012).

To maintain the confidentiality of the study participant information unique number was provided for each client's card number. From client's unique number the sampling frame of PLHIV who were currently on ART was produced and 422 study subjects were selected using computer generated random number. To make the data collection process easier the client appointment date was identified for 422 PLHIV who fulfilled the inclusion criteria. Based on their appointment date the selected PLHIV were interviewed. (Figure 1).

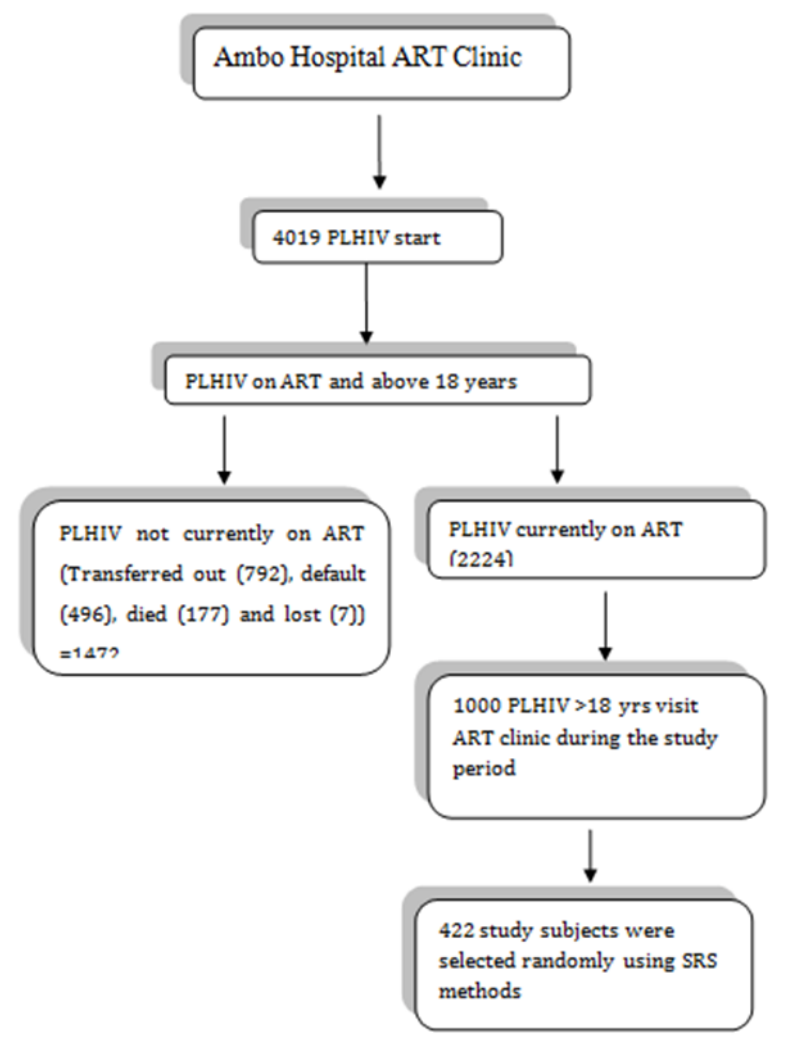

Figure I Schematic presentation of sampling procedure,Ambo Hospital West Shewa Zone, Oromia, 2012.

\section{Data collection procedures}

The data was collected from Jan to Feb 2012 by using structured, standardized and pre-tested questionnaire after it was prepared by reviewing prior studies and other related materials with some modification. ${ }^{16}$ The pretest was done among 21 PLHIV at Gedo Hospital. The questionnaire was prepared in English language and translated into Afan Oromo and back to English. The data collectors and supervisors were trained for two days. They approached PLHIV by introducing themselves and collect information after explaining the purpose of the study by reading the study information sheet. The qualitative data was collected by using semi-structured interview guide to explore the relationship between disclosure and HAART adherence.

\section{Data quality assurance}

Data quality assurance was in place during questionnaire designing, data collection and data entry. The quantitative questionnaire was objective based, logically sequenced, non-leading and pretested. The collected data were checked for completeness, accuracy, clarity and consistency by the supervisor and principal investigator. Daily strict follow-up and checking of the data was done in order to manage any problem encountered. Timely feedback was given for the data collectors and the supervisor. 


\section{Data processing and analysis}

Data were coded, entered and cleaned by using Epi Info version 3.5.1 and imported to SPSS version 16.1 for analysis. The data were summarized in percentages, tables and graphs. Crude and adjusted odds ratios with their 95\% confidence intervals (CIs) using logistic regression analysis were computed to identify factors associated with the outcome variable of interest, HAART adherence.

In multiple logistic regression analysis only variables that had a p-value less than 0.3 were used to avoid an excessive number of variables and unstable estimates in the subsequent model (40). P-value less than 0.05 were considered to see the statistical significance. For the qualitative data narrative analysis was used based on the recording and field notes taken during the interview. The data was transcribed and translated word-by-word for analysis. The qualitative finding was triangulated with the quantitative findings.

\section{Operational definitions}

a. HIV positive status disclosure: Sharing one's own HIV positive diagnostic test result to the partner, family members, friends, etc. ${ }^{17}$

b. Non disclosure: Making secret one's own HIV diagnostic test result. $^{3}$

c. Adherence: Not missing /skipping a dose of ART medication within a week.

d. Non adherence: Missing/skipping at least a dose of ART medication within a week.

\section{Ethical considerations}

The study was undertaken by obtaining ethical clearance from Addis Ababa University, School of public health, Ethical committee. An official letter from the School of Public Health at Addis Ababa University was written to Ambo Hospital to obtain permission to carry out the study at the ART clinic of the hospital. The aim, purpose, benefit and method of the study were clearly explained to the study participants. Written consent was sought from all study participants before the interview.

\section{Result}

\section{Socio- demographic characteristics of the study participants}

A total of 420 PLHIV attending ART clinic at Ambo Hospital participated in the study, giving a response rate of $99.5 \%$. The age of the participants ranged from 18 to 80 years with a mean (SD) of 36.3 $( \pm 9.1)$ years. Of the total participants, $61.9 \%$ were female. Majority $332(79.0 \%)$ of respondents were from urban area. About $88 \%$ of the study participants were Oromo in ethnic group. More than half $(63.3 \%)$ of the respondents were Orthodox Christians.

One hundred eighty two (43.3\%) have attended primary school, $(69.5 \%)$ were unemployed, $240(57.8 \%)$ were married and the median monthly income of the study participant was 300 Ethiopian Birr (Table 1). At the time of the study, the mean duration of ART was $37.9 \pm 23.9$ months. The duration of diagnosis for the study subjects ranged from 3 to 216 months. Fifty $(11.9 \%)$ of the study participants had known their HIV status for less than a year but the rest 370 (88.1\%) knew their status and were living with the virus for more than a year.
Table I Socio-demographic characteristics of PLHIV attending ART clinic in Ambo Hospital, West Shewa Zone, Oromia, 20I2(n=420)

\begin{tabular}{|c|c|c|}
\hline Variables & Frequency & Percent \\
\hline \multicolumn{3}{|l|}{ Residence } \\
\hline Urban & 332 & 79 \\
\hline Rural & 88 & 21 \\
\hline \multicolumn{3}{|l|}{ Age(in years) } \\
\hline $15-19$ & 3 & 0.7 \\
\hline $20-29$ & 94 & 22.4 \\
\hline $\begin{array}{l}30-39 \\
40-49\end{array}$ & $\begin{array}{l}182 \\
100\end{array}$ & $\begin{array}{l}43.3 \\
23.8\end{array}$ \\
\hline $\begin{array}{l}>50 \\
\text { Sex }\end{array}$ & 41 & 9.8 \\
\hline Male & 160 & 38.1 \\
\hline Female & 260 & 61.9 \\
\hline \multicolumn{3}{|l|}{ Ethnicity } \\
\hline $\begin{array}{l}\text { Oromo } \\
\text { Amhara } \\
\text { Other* } \\
\text { Religion }\end{array}$ & $\begin{array}{l}371 \\
38 \\
11\end{array}$ & $\begin{array}{l}88.3 \\
9 \\
2.6\end{array}$ \\
\hline Orthodox Christian & 266 & 63.3 \\
\hline Protestant Christian & 147 & 35 \\
\hline Other** & 7 & 1.7 \\
\hline \multicolumn{3}{|l|}{ Educational status } \\
\hline Illiterate & 122 & 29.05 \\
\hline Primary & 182 & 43.3 \\
\hline Secondary & 80 & 19.05 \\
\hline Above secondary & 36 & 8.6 \\
\hline \multicolumn{3}{|l|}{ Occupation } \\
\hline Employed & 85 & 20.2 \\
\hline Unemployed & 292 & 69.5 \\
\hline Day laborer & 43 & 10.2 \\
\hline \multicolumn{3}{|l|}{ Current marital status } \\
\hline Single & 15 & 3.6 \\
\hline $\begin{array}{l}\text { Married } \\
\text { Divorced }\end{array}$ & $\begin{array}{l}240 \\
83\end{array}$ & $\begin{array}{l}57.8 \\
20\end{array}$ \\
\hline Widowed & 77 & 18.6 \\
\hline $\begin{array}{l}\text { Cohabited } \\
\text { Monthly own income (in ETH. Birr) }\end{array}$ & 5 & 1.2 \\
\hline$<250$ & 135 & 36.9 \\
\hline $25 I-500$ & 126 & 34.4 \\
\hline$>500$ & 105 & 28.7 \\
\hline
\end{tabular}

*Tigre \& Gurage

**Musilm, Catholic \& Joba

\section{Rate of HIV positive status disclosure}

Three hundred sixty two $(86.2 \%)$ of the respondents disclosed their HIV positive status at least to one person and $286(84.9 \%)$ disclosed to their sexual partner but the rest $51(15.1 \%)$ did not disclose their status to their sexual partner. However, for $58(13.8 \%)$ of the respondent disclosure of HIV status was a difficult issue to anyone. The rate of disclosure was achieved over a period of time. Three hundred four $(84 \%)$ of the participants disclosed immediately, $5.9 \%$ between 1 month and 6 month, $10.5 \%$ after 6 months of diagnosis.

As shown in (Figure 2), the first individual to whom the respondents disclosed their HIV result was mainly to family members $273(75.4 \%)$, followed by disclosure to their partners $(67.4 \%)$. 


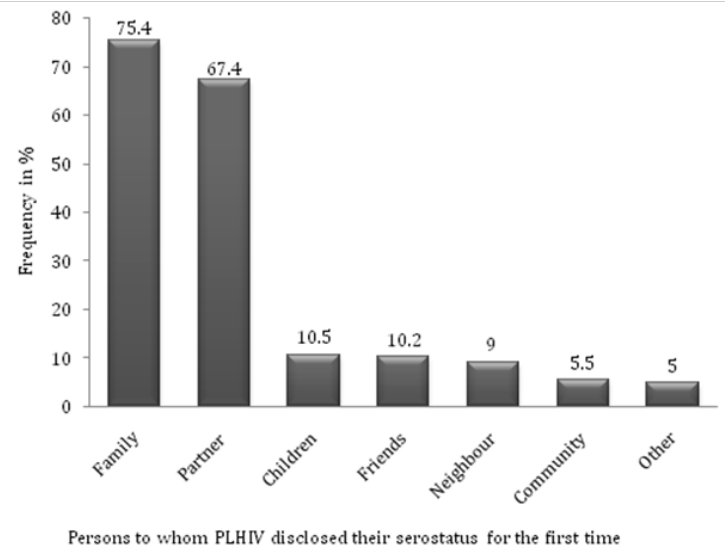

Figure 2 First time HIV positive status disclosures of PLHIV attending ART clinicin Ambo Hospital,West Shewa Zone, Oromia, 2012.

*Percentages do not add up 100\% due to multiple responses

\section{Reasons for non-disclosure}

Reasons for non-disclosure among those respondents who did not disclose their test results to anyone $(\mathrm{n}=58)$ included fear of stigma and discrimination $49(84.5 \%)$, fear of accusation of infidelity 46 (79.3\%), fear of confidentiality $43(74.1 \%)$ and fear of abandonment $6(10.3 \%)$. Whereas the commons reason for non disclosure of their sero status to their partner $(\mathrm{n}=51)$ were fear of accusation of infidelity $40(80 \%)$, fear of confidentiality $35(70 \%)$, fear of stigma $34(68 \%)$ and fear of abandonment 11 (22\%) (Figure 3).

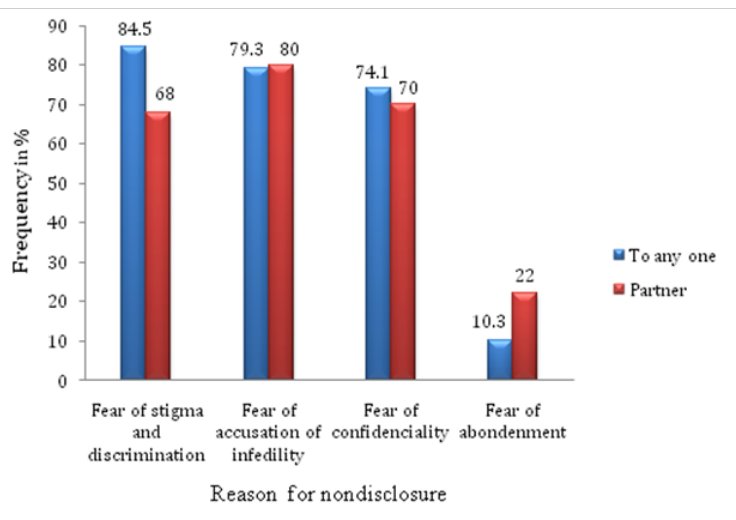

Figure 3 Reason for non disclosure of HIV status to anyone and to their partner of PLHIV attending ART clinic in Ambo Hospital, West Shewa Zone, Oromia, 2012.

*Percentages do not add up 100\% due to multiple responses

\section{Outcomes of HIV status disclosure to sexual partners}

Following disclosure of the HIV test result to their partners, the reaction/response was positive for $239(83.6 \%)$ study participants and negative for 47 (16.4\%) respondents. Positive outcomes following HIV positive sero status disclosure to sexual partner as reported by the respondents were receiving kindness 198 (82.8\%), acceptance $180(75.3 \%)$, increased support $158(66.1 \%)$ and decision to be tested for HIV by the partner $100(41.8 \%)$. The negative outcome commonly encountered following sero status disclosure were anger 37 (78.7\%), blame 34 (72.3\%), stigma 24 (51.1\%), violence $16(34 \%)$, abandonment 14 (29.8\%), and breakup of the relationship 11 (23.4\%).

\section{Rates of HAART adherence, dose missed and reasons for non adherence}

Majority $361(86 \%)$ of the study participants were adherent and the rest $59(14 \%)$ were non adherent based on self report of missed doses (dose adherence) in a one-week recall. Of non adherent $47.5 \%$ of the study participant missed three doses and above, $32.2 \%$ of the respondents missed one dose and the rest $20.3 \%$ of the respondents missed two doses within a week. The most frequent reasons for missed doses were simply forgetting 26 (44.1\%), being with people who did not know their status 26 (44.1\%), being not want to be noticed by others when taking the drugs $17(28.8 \%)$, being away from home 14 $(23.7 \%)$, being busy with other duty16 $(27.1 \%)$ and running out of medication1(1.7\%) (Figure 4).

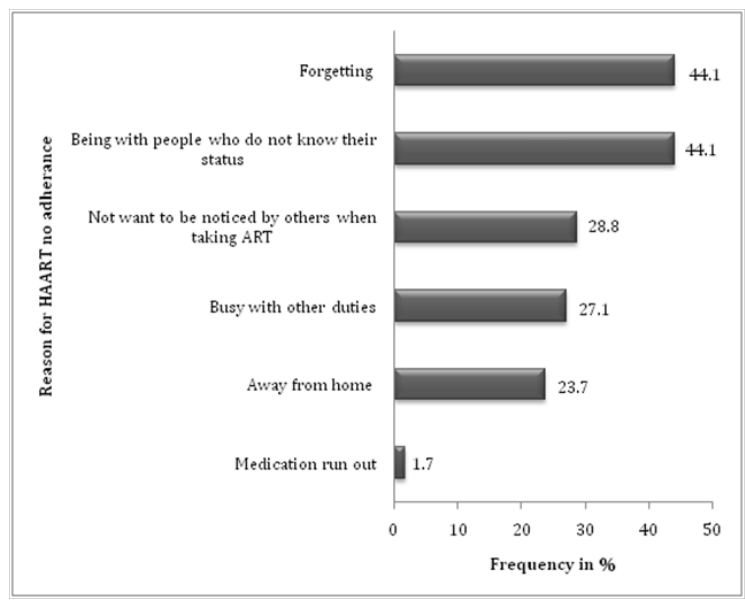

Figure 4 Reasons for non adherence to HAART by study subjects attending ART clinic in Ambo Hospital, West Shewa Zone, Oromia, 2012.

*Percentages do not add up $100 \%$ due to multiple responses

\section{Relationship between HIV status disclosure and ART adherence}

The prevalence of HAART adherence among PLHIV who disclosed their sero status was $88.7 \%$ (95\% CI: 84.95-91.75) where as the prevalence of HAART adherence among PLHIV who did not disclose their status was $69 \%$ (95\% CI: 55.46-80.46). Majority of the study participants $374(89 \%)$ reported that HIV status disclosure and ART adherence were interrelated. This finding was supported by the qualitative study. A 35years old female discussant stated "For how long I took the medication without telling my status?" For example the gust may come in to my house, and also I may away from home to visit others so if they do not know my status how can I take my medication?" Three hundred and seventy six (89.5\%) of the participants stated that HIV status disclosure facilitates initiation and adherence to ART medication.

Of $376(89.5 \%)$ respondents who reported disclosure of HIV sero status facilitates HAART adherence; 309(82.2\%) of them said that disclosure promotes social support, 271(72.1\%) said disclosure facilitates adherence by avoiding fear of stigma and discrimination and the rest $125(33.2 \%)$ respondents reported that disclosure provides psychological support which in turn facilitates ART adherence. Three hundred and eighty four $(91.4 \%)$ of the respondents reported that disclosing owns HIV status to partners, family members and others is important. The importance of disclosure as reported by the respondents were; provides social support 296 (77.1\%), promotes ART adherence 290 (75.5\%), getting relief by sharing secret 220 (57.3\%), avoid non adherence $168(43.8 \%)$ and encourage initiation of ART $118(30.7 \%)$. 
Only $27(6.4 \%)$ of study participants reported disclosure of owns sero status to somebody else promote non adherence to ART medication. Of whom $22(81.5 \%)$ of the respondents reported that they encounter opposition from the person to whom they disclose their status regarding HAART and the rest 12 (44.4\%) reported that discontinuation of HAART due to partner/family objection. Three hundred twenty two $(76.7 \%)$ of the study participants reported that non disclosure affects ART adherence. The qualitative findings also supplement this findings. A 45 year's old female discussant said: "Before I disclosed my status I discontinued the medication for at least four month because I was afraid to take the medication in front of other people. But after I disclosed I take my medication correctly without3 missing any pill since my children remind me.'

Majority $(88.8 \%)$ of the study participants reported that adherence encourages disclosure. Only $46(11 \%)$ of the respondent reported that initiation of ART delays/impedes disclosure but the rest $374(89 \%)$ did not support this idea. Most of the participants (88.8\%) stated that initiation of ART facilitates disclosure. ART treatment initiation facilitated disclosure of HIV sero status through notification, side and therapeutic effects.

\section{Factors associated with HIV positive status disclosure to sexual partner}

In multiple logistic regression analysis marital status $(\mathrm{AOR}=0.13$, 95\%CI: 0.04-0.395), ART initiation (AOR=7.8, 95\%CI: 1.97-31), knowledge of partners HIV status ( $\mathrm{AOR}=5.6,95 \% \mathrm{CI}: 1.9-16.3)$, prior discussion with sexual partner about HIV (AOR=7.5,95\%CI:1.2-46.5) and knowing their HIV status for less than a year $(\mathrm{AOR}=0.05,95 \% \mathrm{CI}$ : 0.007-0.36) and disclosure facilitates ART adherence (AOR=3.6, 95\% CI:0.95-13.6)were significantly associated with HIV status disclosure to their partner. Unmarried respondents were $13 \%$ less likely to disclose their HIV sero status than married participants (AOR $=0.13$, 95\%CI: 0.04-0.395). Respondents who reported ART initiation facilitate HIV status disclosure were 7.8 times more likely to disclose their sero status than those reported ART initiation did not facilitates disclosure(AOR=7.8, 95\%CI: 1.97-31). Knowledge of partners HIV status also associated with HIV sero positive status disclosure to their sexual partner; those participants who know their partner sero status were 5.6 times more likely to disclose their status in comparison with those participants who did not know the HIV status of their partners. Those participants who know as disclosure facilitates ART adherence were 3.6 times more likely to disclose their status than their counter parts.

In addition to this knowing owns sero positivity for less than a year also significantly associated with HIV positive status disclosure. Individuals who had known their HIV status for less than a year was $5 \%$ less likely to disclose their HIV positive status to their partner (AOR $=0.05$, 95\%CI: 0.007-0.36). Participant who had been on ART for less than or equal to one year and smooth relationship with their partner before HIV test were significantly more likely to disclose their HIV positive status to their partner in bivariate analysis but this did not remain significant when controlled for other variables (Table 2).

Table 2 Determinants of HIV positive status disclosure to sexual partner among PLHIV attending ART clinic in Ambo Hospital,West Shewa Zone, Oromia, 2012.

\begin{tabular}{|c|c|c|c|c|}
\hline \multirow{3}{*}{ Variables } & \multicolumn{2}{|c|}{ HIV Status disclosure } & \multirow{3}{*}{$\begin{array}{l}\text { Crude OR } \\
(95 \% \mathrm{Cl})\end{array}$} & \multirow[t]{3}{*}{ AOR $(95 \% \mathrm{Cl}) * *$} \\
\hline & Yes & No & & \\
\hline & No $(\%)$ & No (\%) & & \\
\hline \multicolumn{5}{|l|}{ Marital status } \\
\hline Single & $55(16.6)$ & $37(11.1)$ & $0.092(0.047-0.182)$ & $0.127(0.04-0.395)^{*}$ \\
\hline Married & $226(68.1)$ & $14(4.2)$ & I & 1 \\
\hline \multicolumn{5}{|l|}{ ART Initiation } \\
\hline Yes & $267(79.2)$ & $30(8.9)$ & $0.102(0.049-0.21)$ & $7.8(|.97-3|)^{*}$ \\
\hline No & $19(5.6)$ & $21(6.2)$ & 1 & 1 \\
\hline \multicolumn{5}{|c|}{ Relationship before test } \\
\hline Smooth relation & $217(64.6)$ & $3 I(9.2)$ & $0.49(0.26-0.91)$ & I.2(0.46-3.09) \\
\hline With disagreement & $68(20.2)$ & $20(6.0)$ & I & I \\
\hline \multicolumn{5}{|c|}{ Discuss with partner about hiv issues before test } \\
\hline Yes & $69(20.5)$ & $2(0.6)$ & $0.1(0.03-0.54)$ & $7.5(1.2-46.5)^{*}$ \\
\hline No & $216(64.5)$ & $49(\mid 4.6)$ & I & 1 \\
\hline \multicolumn{5}{|c|}{ Knowledge of partner status } \\
\hline Yes & $266(79.2)$ & $19(5.7)$ & $0.042(0.02-0.088)$ & $5.6(1.9-16.3)^{*}$ \\
\hline No & $19(5.7)$ & $32(9.5)$ & I & 1 \\
\hline \multicolumn{5}{|c|}{ Duration of HIV test } \\
\hline$<12$ month & $18(5.3)$ & $22(6.5)$ & | I.3(5.4-23.5) & $0.052(0.007-0.36)^{*}$ \\
\hline$>12$ month & $268(79.5)$ & $29(8.6)$ & I & 1 \\
\hline \multicolumn{5}{|c|}{ Duration since ART started } \\
\hline$<12$ month & $46(13.6)$ & $22(6.5)$ & $3.96(2.09-7.5)$ & $2.3(0.39-13.1)$ \\
\hline$>12$ month & $240(7 I .2)$ & $29(8.6)$ & 1 & 1 \\
\hline \multicolumn{5}{|c|}{ Disclosure facilitates ART adherence } \\
\hline Yes & $268(79.5)$ & $31(9.2)$ & $0.10(0.05-0.22)$ & $3.6(0.95-13.6)^{*}$ \\
\hline No & $18(5.3)$ & $20(5.9)$ & I & I \\
\hline
\end{tabular}

*P-value $<0.05$ statistically significant

**Adjusted for marital status, ART initiation, relationship before test, discuss with partner about HIV issues before test, duration since ART started, duration of HIV test, knowledge of partner status and disclosure facilitates ART adherence. 


\section{Association of HIV positive status disclosure with HAART adherence}

In bivariate logistic regression analysis disclosure of HIV status to at least one person $(\mathrm{COR}=3.52,95 \% \mathrm{CI}: 1.85-6.71)$, being on ART for more than a year $(\mathrm{COR}=2.24,95 \% \mathrm{CI}$ : 1.23-4.09), employed in occupation (COR=4.24, 95\% CI: 1.32-13.57) and literacy $(\mathrm{COR}=2.79,95 \% \mathrm{CI}: 1.59-4.89)$ were significantly associated with HAART adherence. In multiple logistic regression analysis only educational status and disclosure of HIV status to at least one person were significantly associated with HAART adherence. Respondent who disclosed their sero status to at least one person were 3.5 times more likely to be HAART adherent than those respondent who did not disclose their sero status. (AOR=3.52,95\% CI:1.68-7.37). Educational status of the respondent was also positively associated with HAART adherence. Those study participants who attended formal education or literate respondent were 2.1 times more likely to be adherent than those who were illiterate or could read and write $(\mathrm{AOR}=2.13,95 \%$ CI: 1.08-4.22). However the association found between HAART adherences and being on HAART for one or more years and employed in occupation disappeared after adjusting for other variables (Table 3).

Table 3 Predictors of HAART adherence as reported by PLHIV attending ART clinic in Ambo Hospital, West Shewa Zone, Oromia, 2012

\begin{tabular}{|c|c|c|c|c|}
\hline \multirow{2}{*}{ Variables } & \multicolumn{2}{|c|}{ Adherence to HAART } & \multirow{2}{*}{ COR(95\%CI) } & \multirow{2}{*}{$\operatorname{AOR}(95 \% \mathrm{CI}) * *$} \\
\hline & Adherent & Non adherent & & \\
\hline \multicolumn{5}{|l|}{ Age } \\
\hline$<25$ & $32(78.0)$ & $9(22.0)$ & $0.47(0.11-1.01)$ & $0.69(0.23-2.08)$ \\
\hline $26-35$ & $153(85.0)$ & $27(15.0)$ & $0.74(0.4|-| .35)$ & $0.76(0.39-4.49)$ \\
\hline$>36$ & $176(88.4)$ & $23(I 1.6)$ & I & 1 \\
\hline \multicolumn{5}{|c|}{ Educational status } \\
\hline Illiterate & $93(76.2)$ & $29(23.8)$ & I & I \\
\hline Literate & $268(89.9)$ & $30(10.1)$ & $2.79(1.59-4.89)^{*}$ & $2.13(1.08-4.22)^{*}$ \\
\hline \multicolumn{5}{|l|}{ Occupation } \\
\hline Day laborer & $34(79.1)$ & $9(20.9)$ & I & I \\
\hline Un employed & $247(84.6)$ & $45(15.4)$ & $1.45(0.65-3.24)$ & $0.89(0.34-2.34)$ \\
\hline Employed & $80(94.1)$ & $5(5.9)$ & $4.24(1.32-13.57)^{*}$ & $2.45(0.62-9.62)$ \\
\hline \multicolumn{5}{|l|}{ Income } \\
\hline$<250$ & $115(85.2)$ & $20(\mid 4.8)$ & $0.6 I(0.27-I .37)$ & I.24(0.48-3.II) \\
\hline $25 I-500$ & $105(83.3)$ & $21(16.7)$ & $0.53(0.24-I .17)$ & $0.77(0.32-1.87)$ \\
\hline$>500$ & $95(90.5)$ & $10(9.5)$ & I & I \\
\hline \multicolumn{5}{|c|}{ Month on ART } \\
\hline$<$ lyear & $67(77.0)$ & $20(23.0)$ & I & I \\
\hline$>$ Iyear & $293(88.3)$ & $39(I 1.7)$ & $2.24(1.23-4.09)^{*}$ & $\mathrm{I} .74(0.87-3.5 \mathrm{I})$ \\
\hline \multicolumn{5}{|c|}{ Disclosure of HIV status at least to one person } \\
\hline Yes & $321(88.7)$ & $4 I(I I .3)$ & $3.52(I .85-6.7 I)^{*}$ & $3.52(1.68-7.37)^{*}$ \\
\hline No & $40(69.0)$ & $18(3 \mid .0)$ & I & I \\
\hline
\end{tabular}

*P-value $<0.05$ statistically significant

**Adjusted for age, educational status, income, month on ART and disclose your status at least to one person

\section{Disclosure facilitates HAART adherence}

Almost all participants agree with that of disclosure and HAART adherence had interrelated. Most of the participants reported their family/relatives remind them to take the medication on time. A 36 year's woman said...... "Disclosure is very important! For example, I freely take my medication everywhere even on the street if the time is up I go to someone's home and ask a glass of water and take it. In case if they ask me I tell them that I am taking ART. So people accept and support me. Shortly... disclosure made me free from stress and healthy; you know that... ART itself did not allow stressful condition to work properly so, to make your medication work properly and healthy you should have to free from any stress."

\section{Discussion}

This study was conducted to assess the relationship between HIV positive status disclosure and HAART adherence among PLHIV attending ART clinic of Ambo Hospital in West Showa Zone. The disclosure rate in this study was comparable with study done in Africa.18 The study revealed $86.2 \%$ of the respondents disclosed their status to at least one person while $84.9 \%$ disclosed their status to their sexual partner.

In study conducted in South Africa ${ }^{18}$ it was found that $81 \%$ of the subjects had disclosed their sero status to at least one person. However the studies done in Nigeria, Jimma and Hawassa found higher rate of disclosure than the finding of this study; $97.1 \%, 94.5 \%$ and $92.2 \%$ of the study subjects disclosed their status to at least one person respectively. ${ }^{17-20}$ The reason for lower disclosure rate found in this study might be attributed to the difference in study subjects; in the current study the study subjects were PLHIV who were currently on ART while the pervious study includes all pre-ART and PLHIV on ART.

Similar to other findings. ${ }^{20}$ only $20.1 \%$ and $73.7 \%$ of the respondents reported that they had discussed on HIV and VCT issues prior to the study and knew their partners HIV status respectively. The results of this study were in agreement with many other studies ${ }^{17,20}$ in that knowing a partner's HIV status was found to be associated with the disclosure of one's own status to a partner. 
In this study, based on one-week recall self report of missed doses, the adherence and non adherence rate were $86 \%$ and $14 \%$ respectively. The adherence rate found in this study was comparable with the study conducted in Brazil and Nigeria. ${ }^{21,22}$ with self reported adherence rate of $82 \%, 70.8 \%$ and $85 \%$ respectively.

The study done southwest Ethiopia and Addis Ababa ${ }^{23,24}$ also found almost similar result with this study. Concerning the non adherence rate the finding of this study was similar with the study done in North West Ethiopia ${ }^{25}$ and study conducted in Nigeria ${ }^{26}$ that show non adherence rate $17.3 \%$ and $21.7 \%$ respectively.

The main reasons cited for non adherence were forgetting, being with people who don't know their status and being not want to be noticed by others when taking ART, being away from home and being busy with other duties. The same reasons were mentioned in other studies..$^{27,28}$

Similar to this study non disclosure was mentioned as the main reason for non adherence in studies conducted in New York and Nigeria. ${ }^{13,26}$ Study done in Wolaita and GamoGofa Zones (32) also found non disclosure, simply forgetting and being away from home were the main reasons for non adherence. Studies done in south west Ethiopia $^{23}$ and Yirgalem Hospital ${ }^{29}$ reported that simply forgetting, being busy with other duty and away from home as the main reasons for non adherence. The multivariate logistic regression analyses of this study showed that HIV status disclosure to at least one person had statistically significant association with treatment adherence. This is in line with the findings of other studies conducted in Nigeria, south western Uganda and Thailand. ${ }^{26,27,30}$ Efforts to improve the level of adherence should emphasis on HIV status disclosure to anybody which reduces the fear of stigma and discrimination and increases adherence rate. Study conducted in Nigeria ${ }^{26}$ found that low educational level was significant predictors of non adherence. Education may impact on adherence in several ways including facilitating communication with health workers, increasing retention of information provided by health workers and peer counselors and thereby enhancing implementation of recommendations regarding intake of the antiretroviral drugs ${ }^{31}$

\section{Conclusion}

Majority of PLHIV disclose their sero status to at least one person. Knowledge of partner HIV status, marital status and ART initiation were significantly associated with HIV positive status disclosure to sexual partner. Prevalence of HAART adherence in this study was high. A better HAART adherence was observed among PLHIV who disclosed their sero status to at least one person and those who attended formal education. The most frequently reported reasons for non adherence were forgetting, being with people who did not know their status and do not wanting to be noticed by others when taking ART.

\section{Acknowledgments}

None.

\section{Conflicts of interest}

None.

\section{References}

1. UNAIDS. UNAIDS report on the global AIDS epidemic. Global report. 2013;1-197.

2. Central Statistical Agency and ICF international. Ethiopia Demographic and Health Survey $(E D H S)$ 2011. Addis Ababa, Ethiopia, and Calverton, Maryland. 2012;pp.1-452.
3. Obermeyer MC, Baijal P, Pegurri E. Facilitating HIV disclosure across diverse settings: a review. Am J Public Health. 2011;101(6):1011-1023.

4. Organization WH. Gender Dimension of HIV status disclosure to sexual partners, Rates, Barriers, and outcomes. WHO report. 2004;1-69.

5. Medley A, Garcia Moreno C, Mc Gill SSM. Rates, barriers and outcomes of HIV sero status disclosure among women in developing countries. Bulletin of the WHO. 2004;82(4):299-307.

6. Kadowa I, F Nuwaha. Factors influencing disclosure of HIV positive status in Mityana district of Uganda. Afr Health Sci. 2009;9(1):26-33.

7. Weiser S, Wolfe W, Bangsberg D, et al. Barriers to Antiretroviral Adherence to patients living with HIV infection and AIDS in Botswana. J Acquir Immune Defic Syndr. 2003;34(3):281-288.

8. Biadgilign S, Deribew A, Amberbir A, et al. Barriers and facilitators to antiretroviral medication adherence among HIV-infected pediatric patients in Ethiopia: A qualitative study. Sahara J. 2009;6(4):148-154.

9. Organization WHO. Essential prevention and care interventions for adults and adolescents living with HIV in resource limited settings. World Health Organization report. 2008;1-110.

10. Loubiere S, Peretti Watel P, Boyer S, et al. HIV disclosure and unsafe sex among HIV-infected women in Cameroon: results from the ANRSEVAL study. Soc Sci Med. 2009;69(6):885-891.

11. King R, Katuntu D, Lifshay J, et al. Processes and outcomes of HIV sero status disclosure to sexual partners among people living with HIV in Uganda. AIDS Behav. 2008;12(2):232-243.

12. Do NT, Phiri K, Bussmann $\mathrm{H}$, et al. Psychosocial factors affecting medication adherence among HIV-1 infected adults receivingcombination antiretroviral therapy (cART) in Botswana. AIDS Res Hum Retroviruses. 2010;26(6):685-691.

13. Stirratt MJ, Remien RH, Smith A, et al. The role of HIV sero status disclosure in antiretroviral medication adherence. AIDS Behav. 2006;10(5):483-493.

14. Ding Y, Li L, G Ji. HIV disclosure in rural China: predictors and relationship to access to care. AIDS Care. 2011;23(9):1059-1066.

15. Ramadhani HO, Thielman NM, Landman KZ, et al. Predictors of Incomplete Adherence, Virologic Failure, and Antiviral Drug Resistance among HIV-Infected Adults Receiving Antiretroviral Therapy in Tanzania. Clin Infect Dis. 2007;45(11):1492-1498.

16. Deribe K, Lingerh W, Y D. Determinants and outcomes of disclosing HIV-sero positive status to sexual partners among women in Mettu and Gore towns, Illubabor Zone southwest Ethiop. J Health Dev. 2005;19(2):126-131.

17. Gari T, Habte D, Endrias M. HIV positive status disclosure to sexual partner among women attending ART clinic at Hawassa University Referral Hospital, SNNPR, Ethiopia. Ethiop J Health Dev. 2010;24(1):914.

18. Makin JD, Forsyth BW, Visser MJ, et al. Factors Affecting Disclosure in South African HIV-Positive Pregnant Women. AIDS Patient Care STDS. 2008;22(11):907-916.

19. Igwegbe AO, JO U. Rate and correlates of HIV sero-status disclosure among HIV positive pregnant women in Nnewi southeastern Nigeria. Journal of Medicine and Medical Science. 2010;1(7):296-301.

20. Deribe K, Woldemichael K, Wondafrash M, et al. Disclosure experience and associated factors among HIV positive men and women clinical service users in southwest Ethiopia. BMC Public Health. 2008;8:81.

21. Remien RH, Bastos FI, Jnr VT, et al. Adherence to antiretroviral therapy in a context of universal access, in Rio de Janeiro, Brazil. AIDS Care. 2007;19(6):740-748. 
22. Alakija Kazeem Salami, Fadeyi A, Ogunmodede JA, et al. Factors Influencing Adherence to Antiretroviral Medication in Ilorin, Nigeria. $J$ Int Assoc Physicians AIDS Care (Chic). 2010;9(3):191-195.

23. Tiyou A, Belachew T, Alemseged F, et al. Predictors of adherence to antiretroviral therapy among people living with HIV/AIDS in resource limited setting of southwest Ethiopia. AIDS Res Ther. 2010;7(39):1-10.

24. Tadios Y, Davey G. Antiretroviral drug adherence \& its correlates in Addis Ababa, Ethiopia. Ethiop Med J. 2006;44(3):237-244.

25. Tessema B, Biadglegne F, Mulu A, et al. Magnitude and determinants of non adherence and non readiness to highly active antiretroviral therapy among people living with HIV/AIDS in Northwest Ethiopia. AIDS Res Ther. 2010;7(2):1-8.

26. Igwegbe A, Ugboaja J, L Nwajiaku. Prevalence and determinants of non-adherence to antiretroviral therapy among HIV- positive pregnant women in Nnewi, Nigeria. International Journal of Medicine and Medical Science. 2010;2(8):238-245.
27. Li L, Lee SJ, Wen Y, et al. Antiretroviral therapy adherence among patients living with HIV/AIDS in Thailand. Nurs Health Sci. 2010;12(2):212-220.

28. Duff P, Kipp W, Wild TC, et al. Barriers to accessing highly active antiretroviral therapy by HIV-positive women attending an antenatal clinic in a regional hospital in western Uganda. $J$ Int AIDS Soc. 2010;13(37):1-9.

29. Markos E, Worku A, Gail D. Adherence to ART in PLWHA at Yirgalem Hospital, South Ethiopia. Ethiop J Health Dev. 2008;22(2):174-179.

30. Bajunirwe F, Arts EJ, Tisch DJ, et al. Adherence and Treatment Response among HIV-1-Infected Adults Receiving Antiretroviral Therapy in a Rural Government Hospital in Southwestern Uganda. J Int Assoc Physicians AIDS Care (Chic). 2009;8(2):139-147.

31. Spire B, Carrieri P, Sopha P, et al. Adherence to antiretroviral therapy in patients enrolled in a comprehensive care program in Cambodia: a 24 month follow up assessment. Antivir Ther. 2008;13(5):697-703. 